\title{
BEHAVIOUR OF ALUMINIUM STRUCTURES IN FIRE A review
}

\author{
Davor Skejić, Ivan Ćurković, Marija Jelčić Rukavina \\ University of Zagreb, Faculty of Civil Engineering, Zagreb, Croatia
}

\begin{abstract}
The interest in the application of aluminium as a structural material has been greatly increased in recent years. However, behaviour of aluminium structures when exposed to fire is still relatively unresearched. Due to low melting temperature of the alloy, aluminium structures have low fire resistance, but aluminium is reflective and has surface emissivity which is more than two times lower compared to carbon steel. The Eurocode facing this issue (EN 1999-1-2) is based mainly on the Eurocode for structural fire design of steel structures (EN 1993-1-2) and therefore is not fully suitable for the application on aluminium structures. Here, an overview of the structural behaviour of aluminium structures exposed to fire is given through the comparison with steel structures. As a conclusion, priorities for a future research are highlighted, which should provide a base for the next generation of modern codes for structural fire design of aluminium structures.
\end{abstract}

Keywords: aluminium alloys, structure, fire design, Eurocode

\section{INTRODUCTION}

The interest in the application of aluminium as a structural material has been almost continuously increasing throughout the last century. Its main fields of application have been aeronautic, shipping and automotive industries. Moreover, lightweight materials, such as aluminium alloys are, offer the construction industry an opportunity to design and manufacture high performance structures that are safe, energy-efficient and environmentally friendly, and much lighter than traditional ones. Attraction to aluminium alloys can be attributed to their lightness, versatility of product shapes (extrusion fabrication process), high corrosion resistance, ease of maintenance, good appearance and low-cycle costs, but also to high structural efficiency (large strength to specific weight ratio) (Mazzolani, 1995).

On the other hand, in the field of structural engineering, full utilisation of special features of aluminium has not been always possible, due to lack of technical data and difficulties in the application of special calculation methods required by the peculiar features of the material. This is the case with structural fire design, which is presently carried out by adopting simplified material schematisation and calculation procedures. In fact, while design rules for steel structures subjected to fire are based on comprehensive research activities and laboratory tests as well as long term experience, this is not the case with the aluminium structures. Contrary to steel structures, only few fundamental studies were carried out on fire exposed aluminium structures while there is no experience of aluminium structures in real fires available at all. A scarcity of the available studies led to the conclusion that existing design rules, given in EN 1999-1-2, obviously need improvement.

In almost all cases aluminium alloys need to be protected (insulated) in order to fulfil prescribed fire resistance requirements (Maljaars et al. 2006). Nevertheless, the behaviour of aluminium alloy in fire is thought to be a critical task for the structural design, occurring as consequence of the rapid decrease in the material resistance when exposed to elevated temperatures. Aluminium alloys melt between 600 and $650{ }^{\circ} \mathrm{C}$, the exact value being dependent on the type of alloy under consideration, but at $200-250{ }^{\circ} \mathrm{C}$, most of the alloys will already lose approximately $50 \%$ of their original strength available at room temperature. For this reason, when fire resistance of aluminium structural components is required; the adoption of reliable prediction models would be compulsory. 


\section{ALUMINIUM ALLOYS AT HIGH TEMPERATURES}

\subsection{General}

Generally, aluminium in its alloyed form is a strong ductile metal and has much similarity to structural steel. Due to temperature changes aluminium expansion and contraction is twice as large as that of the steel. However, because of the lower elasticity modulus, temperature stresses in a restrained member are only two-thirds of those stored in steel. Whilst existing code for fire design of steel structures (EN 1993-1-2) is comprehensive, relatively handy and reliable, proposed formulations and methods for aluminium alloys are approximate. In order to consider full capacity of the aluminium and its high vulnerability to fire, more refined models of its mechanical behaviour are required.

\subsection{Material properties at high temperatures}

Relevant values of aluminium alloy properties present at high temperatures, both physical and mechanical, are provided within the EN 1999-1-2. The physical ones allow application of thermal analysis to determine temperature distribution throughout the cross-section, while the mechanical ones allow evaluation of the structure bearing capacity at elevated temperature to be calculated by means of structural analysis. In general, it is crucial to emphasise that almost all material properties are dependent on the alloy type being used. Nevertheless, some common features may be identified, allowing some general trends to be recognised. According to Wald et al., (2002), it has to be noted that:

1. Thermal elongation of aluminium is about $2,5 \cdot 10^{-5}{ }^{\circ} \mathrm{C}^{-1}$ (more than twice that of steel).

2. Specific heat of aluminium alloys ranges from $0,9 \mathrm{~kJ} / \mathrm{kg}^{\circ} \mathrm{C}$ (at room temperature) to 1,1 $\mathrm{kJ} / \mathrm{kg}^{\circ} \mathrm{C}$ (at $500{ }^{\circ} \mathrm{C}$ ), therefore about two times the one of steel.

3. Unlike steel, thermal conductivity of aluminium is increasing together with temperature and ranges from $140-190 \mathrm{~W} / \mathrm{m}^{\circ} \mathrm{C}$ at room temperature to $180-220 \mathrm{~W} / \mathrm{m}^{\circ} \mathrm{C}$ at $400{ }^{\circ} \mathrm{C}$ (more than three times higher than for steel).

4. The emissivity of aluminium surface is dependent on the surface finish, making it difficult to be accurately determined (suggested values are 0,3 for clean uncovered surfaces and 0,7 for painted and covered surfaces (where suggested value for steel is 0,625$)$ ).

From the structural design point of view, the most important difference between aluminium and carbon steel is the shape of the stress-strain curve. In fact, in case of aluminium, the stress-strain curve is nonlinear and there is no well-defined yield stress due to continuous hardening. Besides, it has to be pointed out that there is a great variety of aluminium alloys having mechanical features substantially different from one another in terms of limit strength, ductility and shape of the stressstrain curve, all of which is a consequence of both - the alloy chemical composition and possible type of the applied heat-treatment. On the other hand, the mechanical properties of aluminium present at transient high temperatures are complex and cannot be easily generalised.
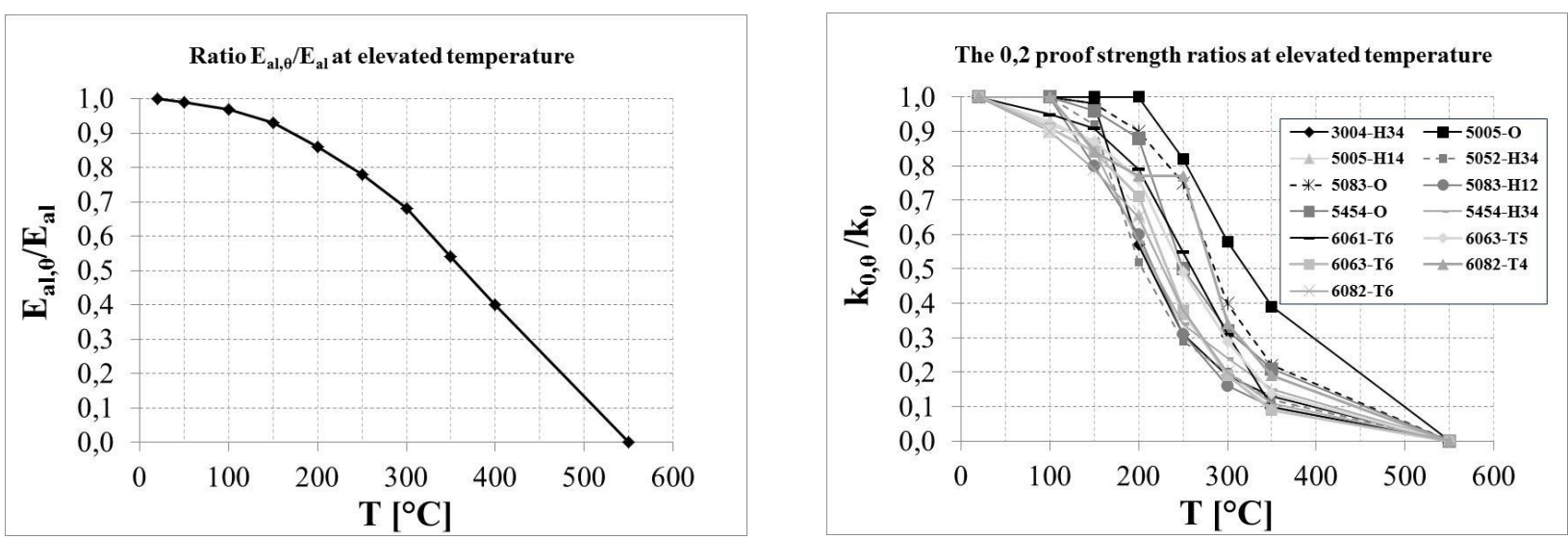

Fig. 1 Main mechanical properties of aluminium at elevated temperatures as suggested by EN 1999-1-2 
The main parameters for the characterisation of aluminium alloys mechanical behaviour within the elastic range are Young's modulus $(E)$ and $0,2 \%$ proof strength $\left(f_{0,2}\right)$, latter being used as conventional elastic limit of the material. While former property is practically independent of the adopted alloy, the latter one is strictly related to the type of alloy under consideration. Figure 1 depicts values suggested by Eurocode 9 for typical aluminium alloys and tempers at elevated temperatures. One can observe the remarkable variation of the conventional elastic limit with temperature $\left(\mathrm{f}_{0,2, \mathrm{~T}}\right)$ for different alloy types and tempers. For instance, relative strength values at $250{ }^{\circ} \mathrm{C}$ are $82 \%$ and $29 \%$ for 5005-O and 5052-H34 alloy, respectively. Even though there is no possibility to form typical common trend among different groups of alloy, it can be noted that the beneficial effects of heat treatment and work hardening diminish at high temperatures.

On the other hand, EN 1999-1-1 does not supply any further information regarding the material behaviour in the plastic range, precluding one to take into account rather important contribution provided by the hardening features of aluminium alloys available at elevated temperatures.

Table 1 Overview of relevant thermal properties of aluminium alloys (Maljaars, 2008)

\begin{tabular}{|c|c|c|}
\hline Thermal property & Status & Remarks \\
\hline Melting temperature & Known & - \\
\hline Density & Known & - \\
\hline Specific heat & Known & $\begin{array}{c}\text { Varies little between alloys. At elevated temperature, only data } \\
\text { on pure aluminium are available. It is assumed that these data } \\
\text { also apply on alloys. }\end{array}$ \\
\hline Thermal conductivity & $\begin{array}{c}\text { Partially known } \\
\text { (but irrelevant) }\end{array}$ & $\begin{array}{c}\text { Varies between alloys at room temperature. At temperatures }> \\
100^{\circ} \mathrm{C} \text {, only data on pure aluminium are available. }\end{array}$ \\
\hline Emissivity & Known & $\begin{array}{c}\text { The exact emissivity of plain aluminium depends on age and } \\
\text { surface. For all covered surfaces, EN 1999-1-2 specifies an } \\
\text { emissivity of 0.7. }\end{array}$ \\
\hline Thermal expansion & Known & - \\
\hline
\end{tabular}

Detailed overview of the relevant thermal and mechanical properties of aluminium alloys is given in (Maljaars, 2008). Table 1 summarises present status of relevant thermal properties, while Table 2 summarises present status of relevant mechanical properties. In conclusion, no further research on thermal properties of aluminium alloys is necessary, while there is lot of research on mechanical properties that needs to be done.

Table 2 Overview of mechanical properties at elevated temperatures of aluminium alloys (Maljaars, 2008)

\begin{tabular}{|c|c|c|}
\hline Mechanical property & Status & Remarks \\
\hline Stress-strain relation & $\begin{array}{c}\text { Insufficiently } \\
\text { known }\end{array}$ & $\begin{array}{c}\text { Less strain hardening is apparent as at room temperature. } \\
\text { The relation depends on the strain rate. However, transient } \\
\text { state tests have not been found in literature, only results of } \\
\text { steady state and creep tests are given. }\end{array}$ \\
\hline Proportional limit & Not known & Not documented for the tensile tests carried out. \\
\hline $0,2 \%$ proof stress & Partially known & $\begin{array}{c}\text { Known for a limited amount of alloys. No transient state } \\
\text { tensile tests were found in literature. }\end{array}$ \\
\hline Tensile strength & Partially known & $\begin{array}{c}\text { Limited information was found on the homogeneous strain } \\
\left(\varepsilon_{\mathrm{b}}\right) .\end{array}$ \\
\hline Weld / HAZ properties & Not known & $\begin{array}{c}\text { The strength of the weld and the HAZ at elevated } \\
\text { temperatures should be determined. }\end{array}$ \\
\hline Modulus of elasticity & Known & For most structural failure mechanisms not relevant. \\
\hline Poisson ratio & Unknown & Creep data are available for a limited number of alloys. \\
\hline Creep & Insufficiently known & and \\
\hline
\end{tabular}




\subsection{Structural behaviour at high temperatures}

Basically, codes regarding aluminium or steel structures exposed to fire, EN 1999-1-2 and EN 1993-1-2 respectively, distinguish same failure mechanisms as at normal temperature design. However, due to changes in material properties as consequence of temperature changes, failure mechanisms may be altered at elevated temperatures.

Additionally, thermal expansion may result in large deformations or, when thermal expansion is partially or entirely restrained, in high internal stresses. Visco-plastic material behaviour may on one hand decrease the material strength, and, on the other hand, result in large deformations and/or relaxation of stresses. The following relevant failure modes of aluminium structures when exposed to fire are distinguished in EN 1999-1-2:

1. The combination of cross-sectional forces applied on a member may exceed the resistance of the cross-section. Cross-sectional forces may be the result of externally applied actions or they may develop due to thermal expansion.

2. Connections between members may fail.

3. Deformations may become such that compatibility between parts of the structure is no longer maintained. Dramatic increase of deformation may be consequence of creep, plastic hinges development, material or connection stiffness reduction and thermal expansion;

4. Buckling occurrence of members partially or entirely in compression. Distinguishable buckling is either entire member buckling or local buckling of the cross-section. Interaction between local and global buckling may also occur.

EN 1999-1-2 provides simple calculation models for individual components. When evaluating individual components, only thermal deformation effects resulting from thermal gradients across the cross-section need to be considered. Additionally, the boundary conditions at supports and ends of a member may be assumed to remain unchanged throughout the duration to fire exposure.

The simple calculation models in EN 1999-1-2 consist of analytical equations covering failure mechanisms of components. The recommended value of partial factor in fire situation is 1,0 . EN 1999-1-2 also provides the possibility to apply advanced calculation models to check an individual component, a part of the structure or to even check the entire structure. In this case, the relevant failure mode during fire exposure, the temperature-dependent material properties and member stiffness, as well as effects of thermal expansion and deformation shall be taken into account. In fire design, deformations at ultimate limit state, implied by the calculation method, shall be limited to ensure that compatibility is maintained between all parts of the structure. Applied advanced calculation models shall be validated based on relevant test results. Sensitivity analyses shall be carried out on critical parameters (buckling length, element sizes and load level).

\section{RESEARCH OVERVIEW}

The behaviour of aluminium in fire has traditionally and continuously been under investigation at the University of Naples Federico II. The general scope of the research activity is the definition of reliable rational methods for structural fire design. Therefore, mechanical models able to account for the material behaviour at elevated temperature in both, elastic and inelastic, ranges have been proposed. These models are based on the well-known Ramberg-Osgood law (Mazzolani 1995), whose parameters are given in a closed-form as a function of the corresponding values at room temperatures and specific temperature-dependent relationships, which have been calibrated on the basis of existing test results (Ponticelli, 1999). In cooperation with University of Liege, the above material model has been introduced into the well know computer program SAFIR (Franssen et al. 1995), allowing the behaviour of complex aluminium structures exposed to standard fires to be predicted up to plastic collapse by means of an accurate but direct and quite simple approach. Recently, an existing constitutive model for creep, developed by Dorn and Harmathy, has been modified in order to be used for fire-exposed aluminium alloys (Maljaars et al. 2008). The existing model was modified to incorporate this first stage of tertiary creep, to arrive at a good agreement between the tests and the modified model for 6xxx series alloys. 
Comprehensive research activities have also been carried out at the NTNU of Trondheim. In particular the behaviour of rectangular hollow cross-section columns made of 6082 different aluminium alloys subjected to fire has been investigated by Langhelle and Amdahl (2001) by means of both experimental tests and complex numerical analyses. Several interesting conclusions are drawn from the above study, emphasizing the necessity to undertake further research activities to obtain more comprehensive database and a better understanding of some fundamental phenomenological aspects which have been evidenced by tested aluminium alloy specimens and are in contradiction with the simplified schematisation suggested by the present design code. This has partially been investigated recently by (Maljaars, 2008) in the research focused on local buckling of slender aluminium sections exposed to fire. Fig. 2 gives a comparison between a selection of the deformed specimens after testing and deformed finite element models for a number of cases. Models show the deformation modes due to large axial deformations, beyond the strain attained at the ultimate buckling resistance. The deformation modes of the various types of analyses in Fig. 2 are similar.
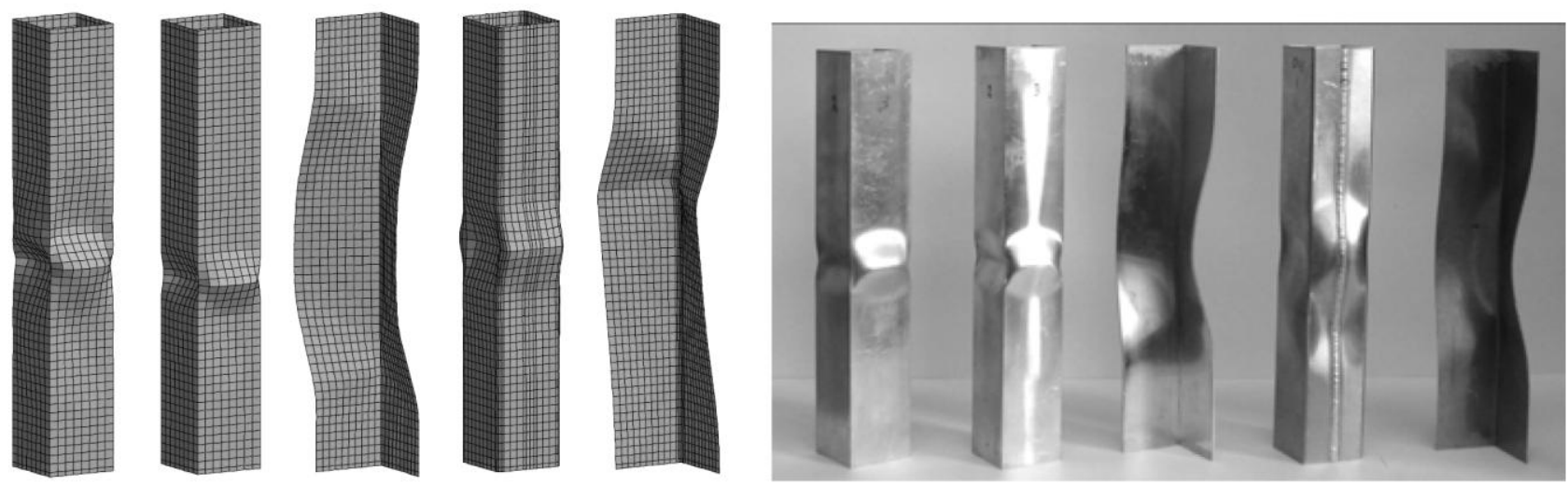

Fig. 2 Selection of deformed models and specimens (Maljaars, 2008)

Stability of aluminium beams in case of fire has most recently been investigated by van der Meulen et al. (2012). Three-point bending experiments have been performed on square hollow aluminium members with varied slenderness ratio values. Interesting conclusions were drawn where it was obvious that the cross-sectional classification system provided in Eurocode 9, EN 1999-1-1 and EN 1999-1-2, with its slenderness limits require further investigation.

\section{FUTURE DEVELOPMENT OF EN 1999-1-2}

Many issues related to the structural behaviour of aluminium exposed to fire still need to be solved in order to allow the designer to apply accurate and rational procedures ensuring safe assessment of aluminium members and structures. Such aspects are concerned with both, use of more realistic material modelling within global structural analysis and the actual response of aluminium members at elevated temperatures.

Up-to-date, only a few fundamental studies were carried out on fire exposed aluminium structures and there has been no experience of aluminium structures in real fires at all. The amount of calculation models provided in the Eurocode for fire design of aluminium structures, EN 1999-1-2, is therefore limited and many calculation models are not validated with the experimental data. For some important failure mechanisms, such as failure of connections and local buckling, no calculation models are incorporated in the code at all.

Second generation of Eurocode sets two main tasks regarding fire design of aluminium alloy structures. First task is the specification of the assessment method for fire protection materials. Upto-date there is no specific method in the ENV 13381 to deal with fire protection materials, therefore further research should be undertaken to cover this application on aluminium structural members. Second task is overall validation of simple calculation methods provided in EN 1999-1-2 that have been mainly developed for steel structures. Only a small number of these calculation 
methods were validated against fire resistance test results conducted on aluminium alloys structures. Thus, current high priority would be validation that needs to be performed between the whole set of calculation methods and tests on real scale structures.

\section{CONCLUSION}

Especially low density, low melting point and high thermal conductivity cause aluminium structures to be fire sensitive. Most of aluminium alloy thermal properties are well known, but most of mechanical properties are determined in steady state tests. Transient state tests, where the temperature increases throughout testing until the critical temperature is reached, and the load is applied from the beginning of heating, provide a better approximation of the real behaviour of materials exposed to fire.

Basically, codes for aluminium and steel structures exposed to fire, EN 1999-1-2 and EN 1993-1-2, distinguish the same failure mechanisms as in normal temperature design. Contrary to steel structures, only few fundamental studies were carried out on fire exposed aluminium structures while no experience of aluminium structures in real fires is available at all. The EN 1999-1-2 provides limited amount of calculation models most of which have not been validated with the experimental data. Furthermore, for some important failure mechanisms (e.g. failure of connections, local buckling) no calculation models are provided within the code at all.

Due to the sensitivity of aluminium to fire conditions, a more realistic approximation of the real behaviour is often required. For this reason Fire Safety Engineering (FSE) is an excellent method to evaluate the fire resistance of aluminium structures. Moreover, the design provisions for fire resistance require some additional improvements, including identification of appropriate active protection systems (e.g. sprinklers), which may enhance the global behaviour of many important structures (i.e. large span roofs, glazing systems, etc.). Finally, an updated code should reduce the penalization of aluminium in competition with other structural materials.

\section{REFERENCES}

EN 1993-1-2, Eurocode 3: Design of steel structures - Part 1-2: General rules - Structural fire design, April 2005 (+AC: 2009)

EN 1999-1-1, Eurocode 9: Design of aluminium structures - Part 1-1: General structural rules, February 2007 $(+\mathrm{A} 1: 2009+\mathrm{A} 2: 2013)$

EN 1999-1-2, Eurocode 9: Design of aluminium structures - Part 1-2: General Rules - Structural fire design, February 2007 (+AC: 2009)

Franssen J.M., Schleich J.B., Cajot L.G. 1995. A simple model for fire resistance of axially-loaded members according to Eurocode 3, Journal of Constructional Steel Research, Vol. 35, p. 49-69.

Langhelle N.K., Amdahl, J. 2001. Experimental and Numerical Analysis of Aluminium Columns Subjected to Fire. In Proc. Eleventh International Offshore and Polar Engineering Conference, 17-22 June, Stavanger, Norway, p. 406-413.

Maljaars J., 2008. Local buckling of slender aluminium sections exposed to fire, $\mathrm{PhD}$ thesis. Eindhoven University of Technology

Maljaars J., Soetens F., Katgerman, L., 2008. Constitutive Model for Aluminum Alloys Exposed to Fire Conditions. Metallurgical and Materials Transactions A, 39 (4), p. 778-789.

Maljaars, J., Twilt, L., Soetens, F. 2006. Heating of aluminium members exposed to natural fire conditions. In Vila Real, Franssen \& Lopes (Eds.), SIF '06 Conference, Aveiro, Portugal, p. 75-88.

Mazzolani, F.M. 1995. Aluminium Alloy Structures - 2nd Edition. E \& FN Spon, London.

Ponticelli L. 1999. Methods for fire safety assessment of aluminium structures, Graduation thesis, University of Naples Federico II (in Italian)

van der Meulen, O.R., Soetens, F., Maljaars, J. 2012. Stability of aluminium beams in case of fire, experiments. In $7^{\text {th }}$ International Conference on Structures in Fire, 6-8 June, Zurich, Switzerland, p. 215223.

Wald F., Bosiljkov V., De Matteis G., Haller P., Vila Real P., 2002. Structural integrity of buildings under exceptional fire, in COST C-12 Seminar: Improving Buildings Structural Quality by New Technologies, 19-20 April, Lisbon, Portugal. 